\title{
Effects of Environmental Temperature and Humidity on Nasal Resistance in Allergic Rhinitis Patients and Healthy Subjects
}

\author{
Kenji Takeuchi, Kensei Naito, Kazuo Sakurai \\ Shoji Saito, Katsuhiko Komori, Hisayuki Katoh
}

Department of Otolaryngology, Fujita Health University, School of Medicine, Aichi

\begin{abstract}
To determine the effects of environmental air temperature and humidity on human nasal air passages, we measured nasal resistance by active anterior rhinomanometry with a nasal nozzle during quiet nasal breathing under totally regulated ambient temperature and humidity in an ambient air controlled room at a cosmetic company and compared the results in allergy patients and healthy subjects. Expiratory nasal resistances in five healthy subjects and four allergic rhinitis patients were measured under the following environmental temperature and humidity conditions : 1) a constant temperature of $20^{\circ} \mathrm{C}$ and $60 \%$ humidity for 20 min, 2) a constant temperature of $20^{\circ} \mathrm{C}$ and $30 \%$ humidity for $20 \mathrm{~min}, 3$ ) a rapid change in environment from a temperature of 35 ${ }^{\circ} \mathrm{C}$ and $60 \%$ humidity for $20 \mathrm{~min}$ to $7^{\circ} \mathrm{C}$ and $60 \%$ humidity for $\left.10 \mathrm{~min}, 4\right)$ a rapid change in environment from a temperature of $35^{\circ} \mathrm{C}$ and $30 \%$ humidity for $20 \mathrm{~min}$ to $7^{\circ} \mathrm{C}$ and $60 \%$ humidity for $10 \mathrm{~min}$. Under steady conditions at a milder temperature $\left[20^{\circ} \mathrm{C}\right]$, there were no changes in nasal resistance in either group of subjects, whether the air was dry $[30 \%]$ or moist $[60 \%]$. When ambient temperature was rapidly changed from warm $\left[35^{\circ} \mathrm{C}\right]$ to cool $\left[7^{\circ} \mathrm{C}\right]$, nasal resistance significantly increased in allergic rhinitis patients, but not in healthy subjects, whether the air was dry or moist. In conclusion, rapid changes in ambient air temperature from warm to cool significantly increased congestion of the nasal mucosa in patients with allergic rhinitis.
\end{abstract}

Key words : nasal resistance, nasal allergy, air temperature, ambient humidity, rhinomanometry

\section{Introduction}

We must breathe air including oxygen into the lungs to remain alive. Environmental air is somewhat cold and dry to breathe directly into the lower respiratory tract. The most important functions of the nose are to warm and to humidify inspired air during its passage through the nose. This air conditioning is of the greatest importance for protection of the mucosa in the lower respiratory tract. The nasal air passages are altered by changes in volume of the susceptible nasal mucosa with variations in environmental air conditions. There have been several studies of local thermal and humidified stimulation of the body, including the dorsal thoracic, foot or hand $\operatorname{skin}^{15,18)}$, and of only inspiratory air stimulation through the nose or mouth ${ }^{4,1014)}$. However, there were no investigations concerning nasal passage under completely controlled environmental temperature and humidity. We therefore measured nasal resistance under totally regulated ambient temperature and humidity using an atmospheric air controlled room at a cosmetic company and compared the results in allergic rhinitis patients and healthy subjects.

\section{Materials and Methods}

Four patients who volunteered, three with nasal allergy to house dust and one with vasomotor rhinitis (two males and two females, mean age 29.8 years) as an allergic group and five non-allergic subjects who volunteered (four males and one female, mean age 28.8 years) as a healthy group were employed for this study. No significant differences were found in age or sex between the groups. Nasal resistances of these subjects were measured under the following environmental tem- 
perature and humidity conditions

Condition 1 : a constant temperature of $20^{\circ} \mathrm{C}$ and $60 \%$ humidity for $20 \mathrm{~min}$.

Condition 2: a constant temperature of $20^{\circ} \mathrm{C}$ and $30 \%$ humidity for $20 \mathrm{~min}$.

Condition 3 : a rapid change in environment from a temperature of $35^{\circ} \mathrm{C}$ and $60 \%$ humidity for $20 \mathrm{~min}$ to a temperature of $7^{\circ} \mathrm{C}$ and $60 \%$ humidity for $10 \mathrm{~min}$.

Condition 4 : rapid change in environment from a temperature of $35^{\circ} \mathrm{C}$ and $30 \%$ humidity for $20 \mathrm{~min}$ to a temperature of $7^{\circ} \mathrm{C}$ and $60 \%$ humidity for $10 \mathrm{~min}$.

The controlled atmosphere room constructed by $\mathrm{Hi}-$ tachi Shimizu Engineering Co., Ltd. of the Biochemical Research Institute of Nippon Menard Cosmetic Co., Ltd. building in Nagoya, Japan, and the storage room $\left(7{ }^{\circ} \mathrm{C}\right.$ with $60 \%$ humidity) in front of the controlled atmosphere room across the corridor were employed to control ambient air conditions.

Unilateral nasal resistances were measured every 5 min during each condition by an MPR-2100 rhinorheograph manufactured by Nihon Kohden Co., Ltd. using active anterior rhinomanometry with a nasal nozzle during quiet nasal breathing. Total nasal resistance was calculated from the equation of Ohm's law for parallel resistors. Values of total expiratory nasal resistance at the peak flow point were determined.

The unpaired t-test was employed to determine the significance of differences for every measurement.

All subjects in this study volunteered and understood well the aim of the study and consented to participate in it.

\section{Results}

Condition 1: Under milder temperature and moist ambient conditions for $20 \mathrm{~min}$, no significant differences in mean values of nasal resistances were found in either the healthy or allergic group, as shown in Figs. 1 and 2.

Condition 2: Under milder temperature and dry ambient conditions for $20 \mathrm{~min}$, no significant differences in means value of nasal resistance were found in either the healthy or allergic group, as shown in Figs. 3 and 4.

Condition 3: With rapid atmospheric change from warm and moist to cool and moist conditions, no signifi-

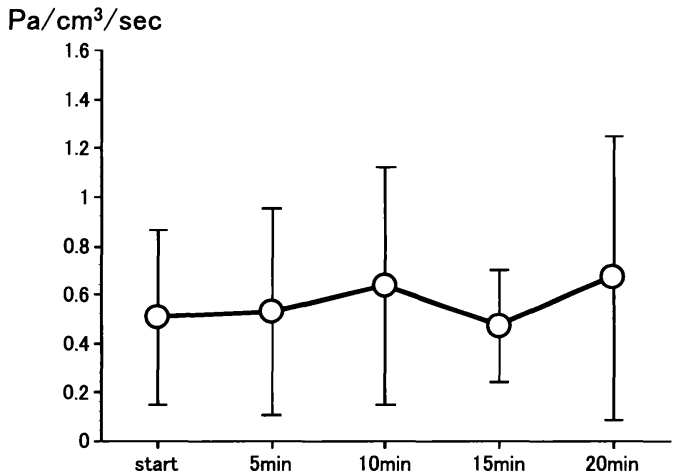

Fig. 1 Changes in mean value and standard deviation of expiratory nasal resistance in normal subjects under stable ambient conditions of $20^{\circ} \mathrm{C}$ and $60 \%$ humidity for $20 \mathrm{~min}$.

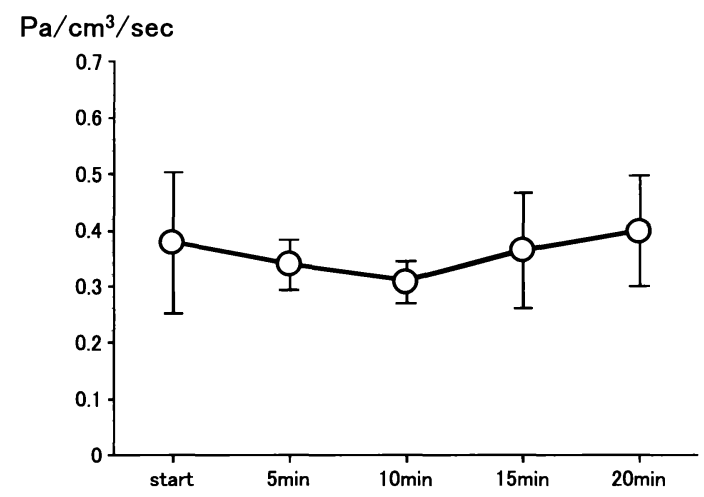

Fig. 2 Changes in mean value and standard deviation of expiratory nasal resistances in patients with nasal allergy under constant ambient conditions of $20^{\circ} \mathrm{C}$ and $60 \%$ humidity for $20 \mathrm{~min}$

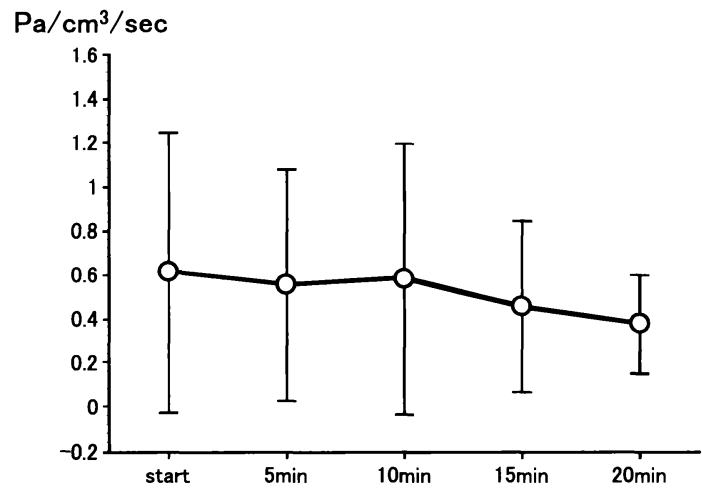

Fig. 3 Changes in mean value and standard deviation of expiratory nasal resistances in normal subjects under constant ambient conditions of $20^{\circ} \mathrm{C}$ and $30 \%$ humidity for $20 \mathrm{~min}$. 


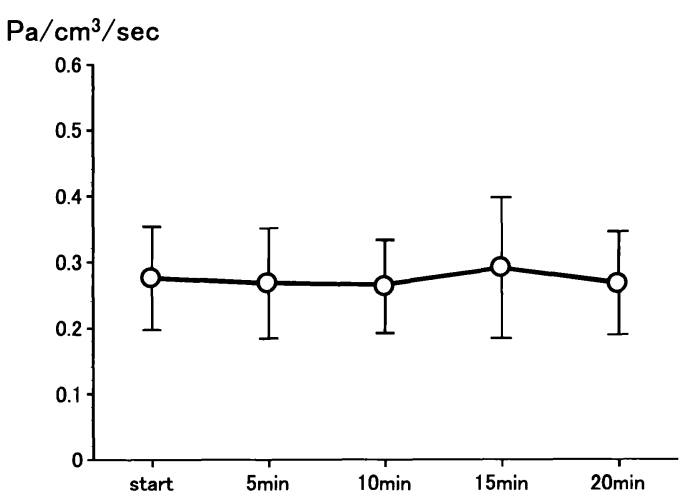

Fig. 4 Changes in mean value and standard deviation of expiratory nasal resistances in patients with nasal allergy under constant ambient conditions of $20^{\circ} \mathrm{C}$ and $30 \%$ humidity for $20 \mathrm{~min}$

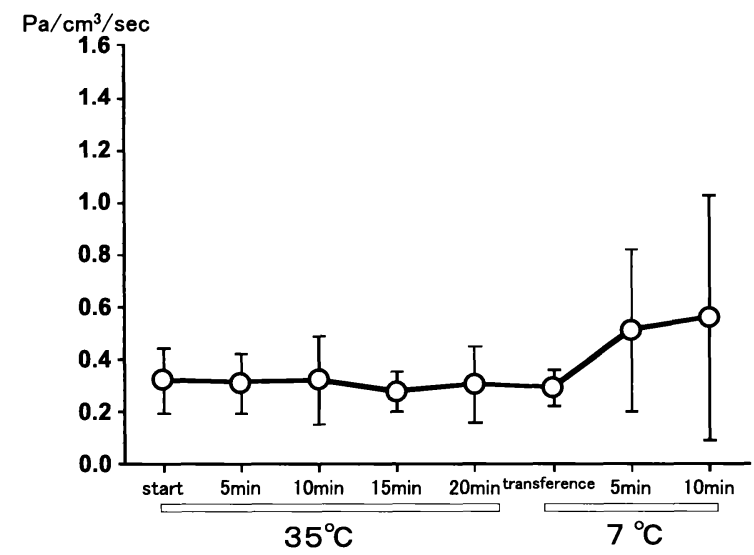

Fig. 5 Changes in mean value and standard deviation of expiratory nasal resistance in healthy subjects under a rapid change from a temperature of $35^{\circ} \mathrm{C}$ and $60 \%$ humidity for 20 min to a temperature of $7{ }^{\circ} \mathrm{C}$ and $60 \%$ humidity for $10 \mathrm{~min}$.

cant alteration in nasal resistance was found in healthy subjects (Fig. 5), but in allergic rhinitis patients mean values of nasal resistance were significantly increased after changing of environmental conditions (Fig. 6). No subjects had sneezing after the change from warm to cool air in either group of subjicts.

Condition 4: With rapid atmospheric change from warm and dry to cool and moist conditions, no significant alteration in nasal resistance was found in healthy subjects (Fig. 7), but in allergic rhinitis patients mean values of nasal resistance were significantly increased after changing of environmental conditions (Fig. 8). No subjects had sneezing after the environmental change from warm to cool air in either group of subjects.

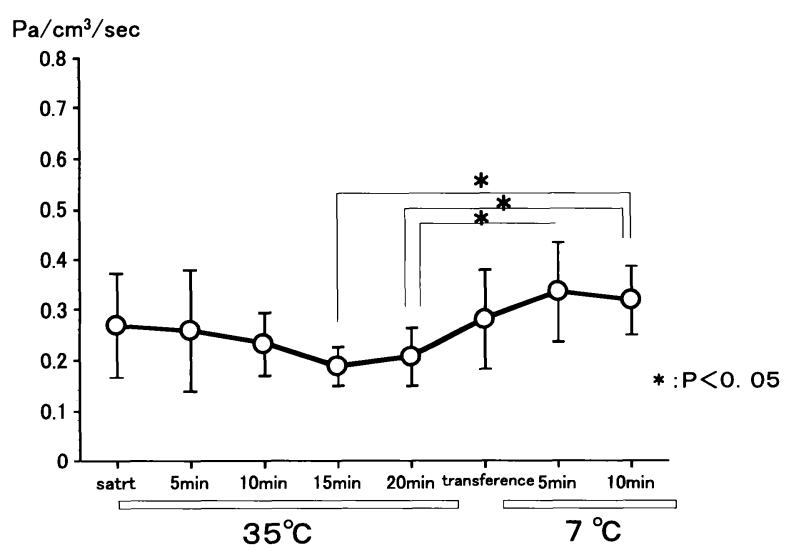

Fig. 6 Changes in mean value and standard deviation of expiratory nasal resistance in patients with nasal allergy under rapid change from a temperature of $35^{\circ} \mathrm{C}$ and $60 \%$ humidity for 20 min to a temperature of $7{ }^{\circ} \mathrm{C}$ and $60 \%$ humidity for $10 \mathrm{~min}$

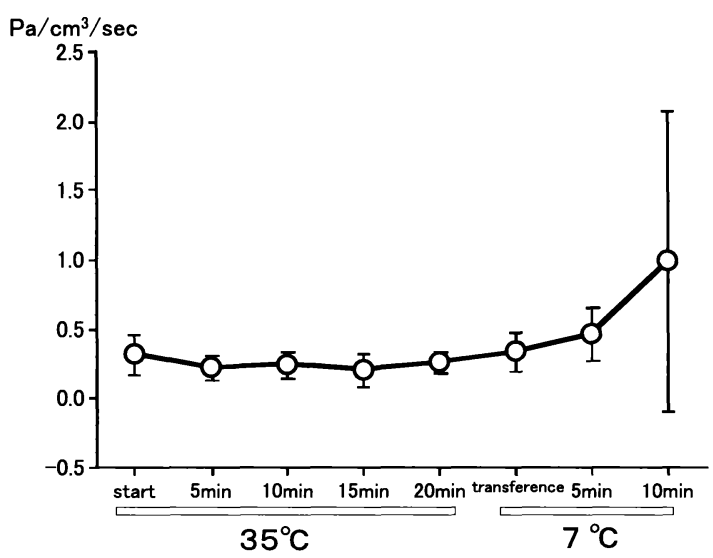

Fig. 7 Changes in mean value and standard deviation of expiratory nasal resistance in healthy subjects under rapid change from a temperature of $35^{\circ} \mathrm{C}$ and $30 \%$ humidity for $20 \mathrm{~min}$ to a temperature of $7^{\circ} \mathrm{C}$ and $60 \%$ humidity for $10 \mathrm{~min}$.

\section{Discussion}

Even at rest, humans breathe $400 \mathrm{~L}$ of air every hour ; this air is cleaned, warmed and moistened on its way to the lungs. The primary importance of ambient air for humans is the provision of oxygen for metabolic processes. The temperature and humidity of inhaled air may vary greatly. Outdoor temperature ranges from -88 to $58^{\circ} \mathrm{C}$, measured at the South Pole and in Libya, respectively. Annual variations together with diurnal patterns and local variations such as altitude or latitude alter conditions of temperature and humidity. Annual vari- 


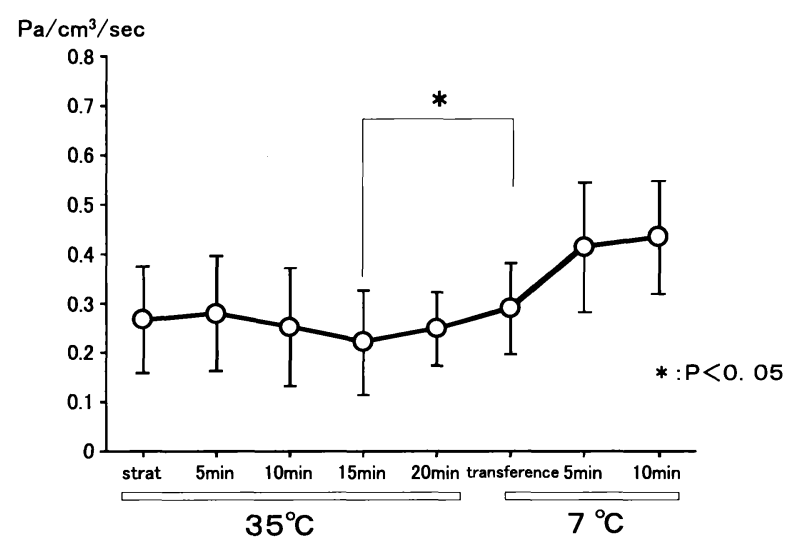

Fig. 8 Changes in mean value and standard deviation of expiratory nasal resistance in patients with nasal allergy under rapid change from a temperature of $35^{\circ} \mathrm{C}$ and $30 \%$ humidity for 20 min to a temperature of $7{ }^{\circ} \mathrm{C}$ and $60 \%$ humidity for $10 \mathrm{~min}$.

ation in absolute humidity generally follows temperature and is higher in the summer than during the winter ${ }^{1)}$.

Two of the most important functions of the nose are to warm and to humidify inspired air during its passage through the nose. This air conditioning is of the greatest importance for protection of the mucosa in the lower respiratory tract. It has been assumed that the nasal turbinates play a role in conditioning inspired $\mathrm{air}^{2)}$.

The normal nasal mucosa spontaneously alters volume due to a reflex upon several types of stimulation, and the rhythm of autonomic nervous system activity is mainly regulated by blood flow in the mucosa ${ }^{11}$. Ambient air conditions, including temperature and humidity, affect alterations of the nasal passage ${ }^{15)}$. Allergic nasal mucosa responds more to various ambient irritants than does normal mucosa ${ }^{12)}$. Naito ${ }^{10)}$ reported that nasal resistances in perennial allergic rhinitis patients were increased after local heated moisturized aerosol stimulation, while there were no changes in nasal resistance in patients without such stimulation and in healthy subjects either with or without hyperthermial stimulation.

There have been several studies of local thermal and humidified stimulation of the body, including the dorsal thoracic, foot or hand $\operatorname{skin}^{18)}$. Most investigators in the 1930s claimed that cooling of localized parts of the skin such as that on the hands, feet, or the back with cold water or air usually caused shrinkage of the nasal mucosa ${ }^{16)}$. In contrast, some recent studies found no definite reaction to cold, or observed swelling ${ }^{13,14,15)}$ in- stead of shrinkage. Dretter ${ }^{4)}$ found a reduction of the temperature of the nasal mucosa in his extensive studies of vascular reactions of the human nasal mucosa to cooling of the back or feet or by cooling of inspiratory air, but observed no obvious or significant change in nasal airway volume during cold exposure. Solomon ${ }^{15)}$ observed nasal obstruction instead of increase in nasal patency during cold exposure. The mechanism of immediate nasal response to local cooling is most likely reflex decrease in nasal blood flow, similar to the well-known vasoconstrictor response in the skin. In canine nasal mucosa, release of nitric oxide from the nitricoxidergic nerve endings is augmented by cold exposure and vasodilatation of nasal blood vessels is enhanced ${ }^{17)}$. They ${ }^{17)}$ also reviewed the unique vascular architecture of the nasal mucosa, the complicated features of innervation by the sympathetic, parasympathetic, and sensory nerves, the effects of some chemical mediators released under some pathologic conditions, and the state of the microcirculation in the nasal mucosa in cases of nasal allergy and cold exposure.

There have been a few reports concerning studies of the nasal passages only under completely controlled environmental temperature $^{9)}$. We therefore measured nasal resistance under totally controlled environmental air temperature and humidity using an atmospheric condition controlled room in a cosmetic company for the present study. The room was constructed primarily for study of the relationships between the skin and cosmetic or skin care products. Using this room, we could stimulate the skin of the entire body and the upper respiratory tract of subjects simultaneously. Under constant conditions of milder temperature $\left[20^{\circ} \mathrm{C}\right]$, there were no changes in nasal resistance in either group of subjects, whether it was dry [20\%] or moist [60\%]. Rapid changes in environmental temperature from warm $\left[35^{\circ} \mathrm{C}\right]$ to cool $\left[7^{\circ} \mathrm{C}\right]$ significantly increased nasal resistance only in allergic rhinitis patients, whether it was dry or moist.

Exercise and postural changes markedly reduce nasal patency ${ }^{6,3,8)}$, and more pronounced effects of exercise on the mucosa were observed in allergic rhinitis patients than in non-allergic subjects ${ }^{7}$. In the present study, we required the allergic rhinitis patients and healthy subjects to remain in sitting position without exercise dur- 
ing all schedules in order to prevent effects of exercise and posture.

In conclusion, rapid changes in ambient air temperature from warm to cool significantly increase congestion of the nasal mucosa in allergic rhinitis patients but not in healthy subjects.

\section{Acknowledgements}

We would like to dedicate this paper to the late Dr. S. Miyata (Department of Otolaryngology, Aichi Prefectural Hospital)

\section{References}

1) Andersen IB, M $\phi$ lhave LARS: The ambient air The nose: upper airway physiology and the atmospheric environment. Elsevir Biomedical Press, New York, pp307-336, 1982.

2 ) Cole P: Modification of inspired air. The nose : upper airway physiology and the atmospheric environment. Elsevir Biomedical Press, New York, pp 351-375, 1982

3 ) Cole P, Forsyth R, Haight JSJ : Effects of air and exercise on nasal patency. Ann Otol Rhinol Laryngol 92 : 196-198, 1983.

4 ) Drettner B : Vascular reactions of the human nasal mucosa on exposure to cold. Acta Otolaryngo Suppl 166 : 9-105, 1961

5 ) Drettner B, Falk B, Simon H : Measurements of the air conditioning capacity of the nose during normal and pathological condition and pharmacological influence. Acta Otolayngol 84 : 266-277, 1977.

6 ) Fouke JM, Jackson AC: Acoustic rhinometry : effects of decongestants and on nasal patency. J Lab Clin Med 199: 371-376, 1992.

7 ) Hilberg O, Grymer LF, Pedersen O : Spontaneous variations in congestion of the nasal mucosa. Ann Allergy Asthma Immunol 74 : 516-521, 1995.

8 ) Kase Y, Hilberg O, Pedersen O : Posture and nasal patency: evaluation by acoustic rhinometry. Acta Otolaryngol (Stockh) 114 : 70-74, 1994.

9 ) Lundqvist G, Pedersen O, Hilberg O, et al: Nasal reaction to changes in whole body temperature Acta Otolaryngol (Stockh) : 113: 783-788, 1993.

10) Naito K, Miyata S, Baba $R$, et al: The alteration of nasal resistance before and after local exposure to heated aerosol in perennial allergic rhinitis. Rhinology 37 : 66-68, 1999.

11) Olsson $P$, Bende $M$ : Influence of environmental temperature on human nasal mucosa. Ann Otol Rhinol Laryngol 94 : 153-155, 1985.

12) Proud D, Bailey GS, Naclerio RM, et al: Tryptase and histamines as markers to evaluate mast cell activation during the responses to nasal challenge with allergen, cold, dry and hyperosmolar solutions. J Allergy Clin Immunol 89 : 1098-1110, 1992.

13) Ralston HJ, Kerr WMJ : Vascular responses of the nasal mucosa to thermal stimuli with some observations on skin temperature. Am J Physiol 144 : 305310,1945

14) Salman SD, Proctor DF, Swift DL, et al : Nasal resistance: Description of a method and effect of temperature and humidity changes. Ann Otol 80 : 736$743,1971$.

15) Solomon WR: Comparative effects of transient body surface cooling, recumbency, and induced obstruction in allergic rhinitis and control subjects. J Allergy 37 : 216-222, 1966

16) Spiesman IG : Vasomotor responses of the mucosa of the upper respiratory tract to thermal stimuli. Am J Physiol 115 : 181-187, 1936.

17) Watanabe $H$, Tsuru H, Yajin $K$, et al : Cold exposure enhances nitrodergic nerve-mediated vasodilatation in canine nasal mucosa. Jpn J Pharmacol 77 : 287-292, 1998

18) Yamagiwa M, Hilberg O, Pedersen O. et al : Evaluation of the effect of localized skin cooling on nasal airway volume by acoustic rhinometry. Am Rev Respir Dis 141 : 1050-1054, 1990.

（2003年 6 月 15 日受稿， 2003 年 9 月 9 日受理）

Reprint and correspondence requests to :

Kenji Takeuchi, M.D.

Department of Otolaryngology,

Fujita Health University, School of Medicine

1-98 Kutsukake Toyoake, Aichi

470-1192 Japan

Tel : 0562-93-9291 Fax : 0562-95-0566 